\title{
Stability of Sorgum, Peanut Blende (Spb) Food Supplement under Ambient Conditions for Treatment of Moderate Acute Malnutrition in Children 6-59 Months
}

\author{
Andrew K. Amegovu ${ }^{1} \&$ Michael Mawadri ${ }^{1}$ \\ ${ }^{1}$ Department of Foods and Sugar Technology, College of Applied and Industrial Sciences, University of Juba, \\ P.O. Box 82, Juba (South Sudan) \\ Correspondence: Andrew K. Amegovu, Department of Foods and Sugar Technology, College of Applied and \\ Industrial Sciences, University of Juba, P.O. Box 82, Juba (South Sudan). E-mail: kiri_andrew@yahoo.com
}

Received: August 1, 2016

Accepted: August 16, $2016 \quad$ Online Published: September 19, 2016

doi:10.5539/jfr.v5n5p82

URL: http://dx.doi.org/10.5539/jfr.v5n5p82

\begin{abstract}
Shelf life is the recommended maximum time for which the defined quality of specified characteristics of the goods or products remains acceptable under expected (or specified) conditions of handling, storage and distribution and or display. Stability assessment of a local food supplement consisting of a premix of milled sorghum, ground nut paste, honey and cow ghee (SPB) was conducted from November 2014to January 2015. The study investigate the length of stay of SPB at ambient conditions with desirable sensory quality attributes of taste, color and texture. This was a cross sectional study design with a sensory evaluation questionnaire using a 5-point hedonic scale. Control sample was labeled as (A) and experimental (B). Sample A was freshly prepared once every week while sample B was kept constant. 24 participants with similar demographic characteristics were randomly selected to evaluated the sensory attributes of the porridges made from each sample. Only the investigator was aware of the treatment given to the participants. Sensory scores for all attributes were greater than four on a five-point hedonic scale. There were no significant differences $(P>0.05)$ in all the five attributes between the two samples in the first 5 weeks of evaluation. A significant difference was observed in color during the week 9 $(\mathrm{P}<0.02)$, aroma in week $6(\mathrm{P}<0.01)$ and taste in week $7(\mathrm{P}<0.01)$. There was no significant difference in the texture of the samples throughout the time of the study. Taste and aroma recorded the lowest scores at 3.0 and 3.7 respectively after 9 weeks. Texture did not change during study time. Honey has anti-microbial properties and its inclusion improves water-binding capacity which prolong shelf life. The length of stay of SPB at room temperature with desirable sensory quality attributes of taste, color and texture was 8 weeks. This storage time could further be increased by use of antioxidants.
\end{abstract}

Keywords: stability, sensory attributes, food supplement (SPB)

\section{Introduction}

The low infant mortality rate (less than 0.5\%) (Macdorman, Mathews, \& Mohangoo, 2014)in industrialized countries is partly explained by their strong support in food diversification and regulations. According to WHO recommendations and guidelines of the European Community (EC) (Juncker, 2015), all foods for infant feeding are carefully enriched with nutrients essential to infant development. Food diversification in industrialized counties can be used as a reference in development of nutritious flours for African children to fight child malnutrition and reduce infant mortality rate.

African diets are predominantly of a starch-rich staple, such as sorghum, with limited amounts of fruits, vegetables, legumes, and pulses, and little or no animal-source food. Such a diet is bulky, has a low density of energy and nutrients and a low bioavailability of minerals, and will result in impaired growth, development, and host defense to infection. Over 2 million children under 5 years in Uganda have undernutrition with the highest stunting and wasting prevalence rates in Karamoja (FANTA-2, 2010). Karamoja is characterized by a long history of droughts and conflict, cattle rustling coupled with poor infrastructure and limited social services leaving a substantial number of households vulnerable to poverty, food insecurity and persistently high malnutrition levels (> 10\%) (DHO/ACF, 2012; WFP \& UNICEF, 2015). Treatment has been limited to imported food supplements with no or limited efforts made to formulate a local, easy to make at household level and 
sustainable formulas. These imported therapeutic/or supplementary foods are costly (de Pee, S.D. and M.W. Bloem, 2008)for an already low income country(World Bank, 2016).

A local supplementary food (SPB) consisting of sorghum, peanut blended with honey and ghee was developed (Amegovu et al., 2013) to treat moderate acute malnutrition. Its efficacy and sensory acceptability were previously reported (Amegovu et al., 2014). Indigenous grains such as sorghum, millet especially in Africa are not being used to their full potential as a result of importation and price subsidies on wheat (Macauley, 2015). Sorghum is the staple food in Karamoja (Mwesigwa et al., 2014). Owing to a low moisture content, cereals and pulses are relatively stable during storage and are processed to change the eating quality and add variety to the diet. Honey is a natural sweetener with high energy carbohydrate and antioxidant (Eteraf-oskouei \& Najafi, 2013), antimicrobial (Shultz, 2009) and antifungal properties (Golden, 2009). Growth of bacterial species such as Escherichia coli, Staphylococusaureus Salmonella typhimurium and Shigella sp. are controlled by honey through its antimicrobial characteristics (Abeshu \& Geleta, 2016) (osmotic effect, acidity, $\mathrm{H}_{2} \mathrm{O}_{2}$, flavonoids and aromatic acidic substances). Cow ghee is a rich source of lipids which impart nutritious value as a source of metabolic energy, essential fatty acids (linoleic, linolenic and arachidonic) and fat soluble vitamins (D, E, A, and K) (Allen J. St. Angelo., 1996).

However, the stability of the local food supplements as complementary foods to treat moderate acute malnutrition among children has not been widely studied and documented. Shelf life is the recommended maximum time for which products or fresh (harvested) produce can be stored, during which the defined quality of a specified proportion of the goods remains acceptable under expected (or specified) conditions of distribution, storage and display (Gyesley, S. W., Henyon DK, 1991). This study examines the shelf life of a food supplement formulated from sorghum blended with honey, peanut and cow's ghee as complementary foods to infant diet, a case of pastoral diet in Karamoja region. This could enhance knowledge and practices that can significantly improve community efforts to manage cases of acute malnutrition using sorghum peanut blend.

\section{Materials and Methods}

\subsection{Study Design}

This was a cross sectional study with a sensory evaluation questionnaire using a 5-point hedonic scale.

\subsection{Study Setting and Study Population}

This study was conducted between November 2014 and January 2015, in Nakapiripirit district. Nakapiripirit is a village setting in Karamoja region, Uganda. The area is inhabited by Karamajongs who are predominately nomadic pastoralists. The participants were randomly selected to eliminate bias. They were literates who could answer the sensory evaluation form. Participants who were non-consenting and had allergic complications towards the foods used for the formulation were excluded. A total of 24 caregivers were involved in the study.

\subsection{Preparation and Formulation of Sorghum Peanut Blend}

Raw materials used comprised of sorghum, groundnuts, ghee and honey. These food materials were locally procured from markets in northeastern Uganda. Sorghum and groundnuts were sun dried for five days to moisture levels below $10 \%$. Sorghum was cleaned by winnowing to remove damaged kernels, non-grain plant materials and any other extraneous matter. Dirt free sorghum was then milled into flour. Groundnuts were hand sorted to remove damaged and shriveled kernels and any foreign matter. The groundnuts were roasted for 30 minutes using a charcoal stove before grinding to a semi-coarse paste. Milk from Karamajong Zebu cows was traditionally processed by fermentation for three days in pots. Fermented milk was churned by hand in a plastic jerry-can until butter granules clumped on the top. The butter granules were scooped off, washed to remove the butter milk and then matured for one week to develop the desired flavor. The ghee was boiled using a charcoal stove for 30 minutes to destroy any microorganisms. Nutri-survey computer software, employing linear programming technique, was used to generate appropriate component ratios (Erhardt, 2014).The quantity of each raw material depended on composition and the recommended daily allowances(Golden, 2009)for children between 6 to 59 months of age.

\subsection{SPB Acceptability}

Control (A) and experiment (B) samples SPB were prepared. Sample A was freshly prepared once every week. Sample B was packaged in an air tight polyethylene and kept at room temperature $\left(25^{\circ} \mathrm{C}\right)$. Porridges were prepared from each sample every week for 3 months. Each participant was provided with $150 \mathrm{~mL}$ (made by mixing $290 \mathrm{~g}$ of SPB 1 in 1L of water) of porridge in a graduated cup. Participants randomly selected evaluated the sensory attributes of the porridges. Only the investigator was aware of the treatment (the nature of the food supplement) given to the participants. The color, aroma, taste, texture and overall acceptability of the prepared 
porridges were evaluated based on a 5-point hedonic scale (Meilgaard, M., Civille, G. V., \& Carr, 2007).

\subsection{Data Analysis}

Data was analyzed using computer statistical software of SPSS 17.0 (Bryman, A., \& Cramer, 2011). Differences between means of sensory parameters; color, aroma, taste, mouth feel, consistency and overall acceptability were tested for significance using the least significance difference (LSD) at $95 \%$ confidence level $(\mathrm{P}<0.05)$.

\section{Results}

\subsection{Characteristics of the Participants}

Study group had a similar demographic characteristics, the participants were all female, of the same age bracket and had all completed basic primary education.

\subsection{Sensory Attributes}

The attributes of porridge A and B evaluated were; color, aroma, taste, texture and overall acceptability as shown in Table 1. Sensory scores for all attributes were greater than four on afive-point hedonic scale. There were no significant differences $(\mathrm{P}<0.05)$ in all the five attributes between the two samples in the first 5 weeks of evaluation. A significant difference in samples $\mathrm{A}$ and $\mathrm{B}$ was observed in color during the week $9(\mathrm{P}<0.02)$, aroma in week $6(\mathrm{P}<0.01)$ and taste in week $7(\mathrm{P}<0.01)$. There was no significant difference in the texture of the samples throughout the time of the study.

Table 1. Sensory attributes of SPB during storage

\begin{tabular}{lllllll}
\hline Time & Sample & \multicolumn{2}{l}{ Sensory Attributes } & & & \\
\hline & & Color & Aroma & Taste & Texture & Overall acceptability \\
\hline Week 1 & $\mathrm{A}$ & $8.1 \pm 0.87$ & $7.6 \pm 0.52$ & $7.5 \pm 0.97$ & $6.9 \pm 1.52$ & $7.8 \pm 0.79$ \\
& $\mathrm{~B}$ & $7.6 \pm 0.84$ & $7.6 \pm 0.51$ & $7.4 \pm 0.97$ & $6.6 \pm 2.4$ & $7.7 \pm 0.95$ \\
& P-value & 0.273 & 1 & 0.823 & 0.671 & 0.823 \\
\hline Week 2 & $\mathrm{A}$ & $7.7 \pm 0.48$ & $7.6 \pm 0.70$ & $7.8 \pm 0.79$ & $6.7 \pm 1.77$ & $7.9 \pm 1.0$ \\
& $\mathrm{~B}$ & $7.6 \pm 0.52$ & $7.3 \pm 0.67$ & $7.1 \pm 0.32$ & $6.3 \pm 2.00$ & $7.2 \pm 1.32$ \\
& P-value & 0.678 & 0.279 & 0.251 & 0.583 & 0.298 \\
\hline Week 3 & $\mathrm{A}$ & $7.3 \pm 0.48$ & $7.5 \pm 0.53$ & $7.3 \pm 0.95$ & $7.0 \pm 0.94$ & $7.1 \pm 0.74$ \\
& $\mathrm{~B}$ & $7.2 \pm 0.63$ & $7.4 \pm 0.52$ & $6.9 \pm 0.88$ & $6.5 \pm 1.10$ & $6.9 \pm 0.57$ \\
& P-value & 0.678 & 0.678 & 0.343 & 0.213 & 0.591 \\
\hline Week 4 & $\mathrm{A}$ & $7.7 \pm 0.67$ & $7.4 \pm 0.70$ & $7.4 \pm 0.52$ & $7.7 \pm 0.95$ & $7.6 \pm 0.84$ \\
& $\mathrm{~B}$ & $7.6 \pm 0.70$ & $6.5 \pm 0.71$ & $7.1 \pm 0.57$ & $7.1 \pm 0.74$ & $7.5 \pm 0.85$ \\
& $\mathrm{P}$-value & 0.726 & 0.102 & 0.193 & 0.151 & 0.758 \\
\hline Week 5 & $\mathrm{A}$ & $7.0 \pm 0.82$ & $6.3 \pm 0.82$ & $6.3 \pm 1.34$ & $7.0 \pm 0.94$ & $6.2 \pm 2.04$ \\
& $\mathrm{~B}$ & $6.9 \pm 1.29$ & $6.1 \pm 1.45$ & $6.1 \pm 1.52$ & $6.7 \pm 2.00$ & $5.9 \pm 1.45$ \\
& $\mathrm{P}$-value & 0.758 & 0.662 & 0.764 & 0.708 & 0.541 \\
\hline Week 6 & $\mathrm{A}$ & $7.9 \pm 0.86$ & $7.1 \pm 1.20$ & $6.8 \pm 1.55$ & $6.5 \pm 1.08$ & $6.4 \pm 1.78$ \\
& $\mathrm{~B}$ & $6.9 \pm 0.74$ & $5.3 \pm 1.70$ & $5.9 \pm 1.85$ & $5.8 \pm 1.32$ & $6.3 \pm 1.57$ \\
& $\mathrm{P}$-value & 0.052 & 0.01 & 0.343 & 0.102 & 0.242 \\
\hline Week 7 & $\mathrm{A}$ & $6.9 \pm 1.10$ & $6.4 \pm 1.43$ & $6.9 \pm 0.99$ & $6.8 \pm 0.92$ & $6.9 \pm 0.99$ \\
& $\mathrm{~B}$ & $6.8 \pm 0.92$ & $5.9 \pm 1.79$ & $5.8 \pm 1.62$ & $5.9 \pm 1.66$ & $6.3 \pm 1.83$ \\
& P-value & 0.832 & 0.464 & 0.01 & 0.225 & 0.468 \\
\hline Week 8 & $\mathrm{A}$ & $6.6 \pm 0.52$ & $7.6 \pm 0.97$ & $7.4 \pm 1.43$ & $7.0 \pm 1.33$ & $7.9 \pm 0.88$ \\
& $\mathrm{~B}$ & $6.3 \pm 1.77$ & $5.7 \pm 0.82$ & $5.4 \pm 1.65$ & $6.8 \pm 1.73$ & $5.5 \pm 1.65$ \\
& $\mathrm{P}$-value & 0.664 & 0.001 & 0.005 & 0.06 & 0.001 \\
\hline Week 9 & $\mathrm{A}$ & $7.3 \pm 1.64$ & $6.7 \pm 1.16$ & $6.9 \pm 1.58$ & $6.8 \pm 1.81$ & $7.9 \pm 0.88$ \\
& $\mathrm{~B}$ & $5.3 \pm 1.42$ & $3.7 \pm 1.06$ & $3.0 \pm 1.63$ & $6.9 \pm 1.78$ & $3.7 \pm 0.95$ \\
& $\mathrm{P}$-value & 0.002 & 0 & 0.001 & 0.06 & 0.002 \\
\hline
\end{tabular}

*values in the same Colum in each segment with different superscripts are significantly different $(\mathrm{P}<0.05)$

Difference in acceptability of the two samples was observed after 8weeks $(\mathrm{P}<0.001)$ table.1 


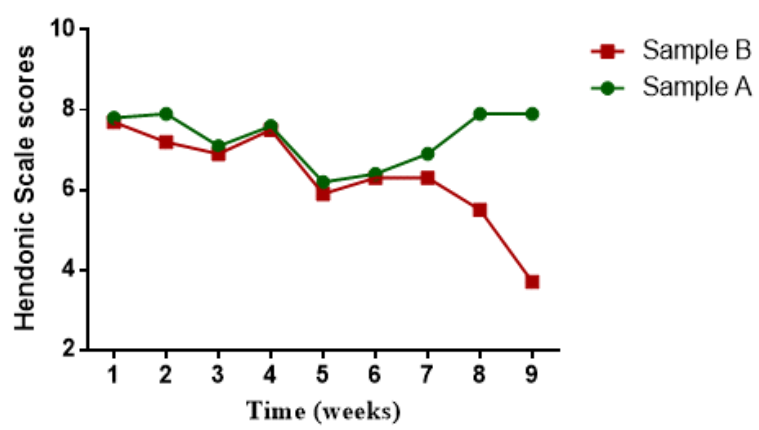

Figure 1. Overall acceptability of SPB over time

The acceptability of sample A's did not change much with time while acceptability of sample B decreased over time as shown in Fig 1. Overall acceptability of sample A and B diverged during week 6. During week 8 and 9 sample B scores were 5.5 and 3.7 respectively compared to scores of 7.9 and 7.9 for sample A over the same period.

\subsection{Storage Time of SPB}

Throughout the storage time, taste, aroma and color of SPB (sample B) decreased with time while texture remained constant. All the sensory attributes scored very highly (>7) for the first 4 weeks (Fig 2) and above 5 after 8 weeks. The highest scores were recorded with color and aroma at 7.6 in week 1 and 4.The lowest scores were observed in the taste ( 3.0 score) and aroma ( 3.7 score) after 9 weeks.

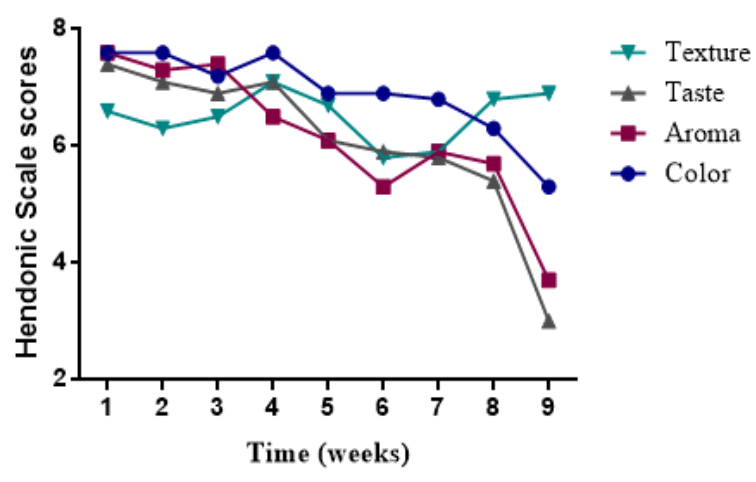

Figure 2. Sensory attributes of sample B of SPB during storage

\section{Discussion}

Sorghum peanut blend (SPB) food supplement recorded a high overall acceptability. The experiment (sample B) was still acceptable after 8 weeks. This may be due to the inclusion of honey which offers functional benefits, improve water-binding capacity, provide and improves shelf life (Addo, 1997; Chan \& Foster, 2008)thus prolonging the shelf life of SPB naturally. In addition the anti-microbial properties of honey could delay spoilage (Abeshu \& Geleta, 2016). Sorghum used in the formulation has a low moisture content (Jean du Plessis., 2008)hence making the product relatively stable during storage. Coarse sorghum used has a longer shelf life of up to 45 days than the medium and fine sorghum.

The color of SPB scored highly for both the control (sample A) and the experiment (sample B). This may be due to the different types of foods used that give SPB a favorable color. Change in color $(\mathrm{P}<0.01)$ was only observed after 9 weeks. This could be due to lipid oxidation of fatty acids in the cow ghee leading to rancidity (Wsowicz et al., 2004) hence changing the color of the product. The fat and water content in food determine the aroma and taste-relevant ions and compounds(Thomas A Vilgis., 2013). However oxidation over time could lead to the development of off flavors and off odors(Allen J. St. Angelo., 1996; Wsowicz et al., 2004)hence deteriorating the aroma. Oxidation is activated by presence of UV light and oxygen during storage. Aroma and taste are closely linked. This was evidenced by the shape decline of both aroma and taste after 9 weeks (3.7 and 3.0 scores respectively). Taste was highly contributed by honey in SPB due its composition of fructose and glucose (Eteraf-oskouei \& Najafi, 2013). The texture of both samples did not vary significantly during the study and 
storage time had effect on texture. The physical structure define the texture of the food(Thomas A Vilgis., 2013) and this did not change during the study.

In conclusion, the length of stay of SPB at ambient temperatures with desirable sensory quality attributes of taste, color and texture was 8 weeks. Texture did not change during storage while aroma and taste decreased with storage time. Antioxidants should be used to increase the storage time.

\section{Acknowledgements}

We are particularly grateful to the participants who accepted to take part in this study.

\section{Conflicts of interest}

The authors declare that they have no conflicts of interest.

\section{References}

Abeshu, M. A., \& Geleta, B. (2016). Medicinal Uses of Honey. Biol Med (Aligarh), 8(2), 1-7. http://doi.org/10.4172/0974-8369.1000276

Addo, K. (1997). Effects of honey type and level on the baking properties of frozen wheat flour doughs. Cereal Foods World (USA), 42, 36-40.

Allen J. St. Angelo. (1996). Lipid Oxidation In Foods. Critical Reviews in Food Science and Nutrition, 36(3), 175-225. http://dx.doi.org/10.1080/10408399609527723

Amegovu, A. K., Ochola, S., Ogwok, P., Yiga, P., Musalima, J., \& Juliana, M. (2014). Efficacy of sorghum peanut blend and corn soy blend plus in the treatment of moderate acute malnutrition in children aged $6-59$ months in Karamoja , Uganda : a cluster randomized trial. Nutrition and Dietary Supplements, 6, 75-84. http://doi.org/hhtp://dx.doi.org/10.214/NDS.S64720

Amegovu, A. K., Ochola, S., Ogwok, P., Yiga, P., Musalima, J., \& Mutenyo, E. (2013). Formulation of Sorghum-peanut blend using linear programming for treatment of moderate acute malnutrition in Uganda. Journal of Food Chemistry and Nutrition, 01(02), 67-77.

Bryman, A., \& Cramer, D. (2011). Quantitative data analysis with IBM SPSS 17, 18 and 19. Routledge.

Chan, Q. W. T., \& Foster, L. J. (2008). Changes in protein expression during honey bee larval development, 9(10). http://doi.org/10.1186/gb-2008-9-10-r156

Pee, S. D., \& M. W. Bloem. (2008). Current and potential role of specially formulated foods and food supplements for preventing malnutrition among 6-23 month old and treating moderate malnutrition among 6-59 months old children. WHO in collaboration with WFP, UNICEF, UNHCR. Geneva.

DHO/ACF. (2012). Nutrition Surveillance Karamoja Region, Uganda; Nutritional Surveillance Report.

Erhardt, J. (2014). Nutrisurvey software version 2007. [Updated 2012/04/04; cited 2007/08/08]. Retrieved from Http://www.nutrisurvey.de/

Eteraf-oskouei, T., \& Najafi, M. (2013). Traditional and Modern Uses of Natural Honey in Human Diseases : A Review. Iranian Journal of Basic Medical Sciences, 16, 731-742.

FANTA-2. (2010). The Analy ysis of the Nutrition Situation in Uganda. Food and Nutrition Technical Assistance II Project (FANTA-2). Washington (DC).

Golden, M. (2009). Proposed nutrient requirements of moderately malnourished populations of children. FoodNutrition Bulletin, 30, S237-S342. http://dx.doi.org/10.1177/15648265090303S302

Gyesley, S. W., Henyon DK, E. (1991). Total systems approach to predict shelf life of packaged foods. AStM International : Food Packaging Technology, 46-50. http://doi.org/10.1520/STP14842S

Jean du Plessis. (2008). Sorghum production. Department of Agriculture. Retrieved from www.nda.agric.za/publications

Juncker, J. C. (2015). Commission Delegated Regulation (EU); supplementing Regulatin (EU) No 609/2013 of the European Parliament and of the Council as regards the specific compositional and information requirements for processed cereal-based food and baby food, 2015 European Commission.

Macauley, H. (2015). Feeding Africa. Cereal Crops: Rice, Maize, Millet, Sorghum, Wheat. Dahar, Senegal.

Macdorman, M. F., Mathews, T. J., \& Mohangoo, A. D. (2014). National Vital Statistics Reports International Comparisons of Infant Mortality and Related Factors : United States and Europe, 2010 (Vol. 63). 
Meilgaard, M., Civille, G. V., \& Carr, B. T. (2007). Overall difference tests: does a sensory difference exist between samples. Sensory Evaluation Techniques, 4, 63-104.

Mwesigwa, B., Bushara, D. N., Tusiime, H., Twanza, E., Gule, S., Odong, J., ... Ocen, D. (2014). KARAMOJA FOOD SECURITY ASSESSMENT.

Shultz, S. M. (2009). Honey as a remedy. In: Alternative and complimentary therapies, edited by Shultz, S. M. and Esther Y. D. Journal of Consumer Health, 13, 287-294. http://dx.doi.org/10.1080/15398280903120034

Thomas, A. Vilgis. (2013). Texture, taste and aroma : multi-scale materials and the gastrophysics of food. Flavour, 2(12). http://doi.org/10.1186/2044-7248-2-12

WFP \& UNICEF. (2015). Food security \& nutrition assessment.

World Bank. (2016). Low-income economies ( $\$ 1,025$ or less). Retrieved May 7, 2016, from https://datahelpdesk.worldbank.org/knowledgebase/articles/906519

Wsowicz, E., Gramza, A., Hêœ, M., Jeleñ, H. H., Korczak, J., Maecka, M., ... Rudziñska, M. (2004). Oxidation of lipids in food. Polish Journal of Food and Nutritional Sciences, 13(48 61), 87-100.

\section{Copyrights}

Copyright for this article is retained by the author(s), with first publication rights granted to the journal.

This is an open-access article distributed under the terms and conditions of the Creative Commons Attribution license (http://creativecommons.org/licenses/by/4.0/). 